\title{
Sensorless Position Tracking for Steer-by-Wire Applications
}

\author{
K. Scicluna \\ C. Spiteri Staines \\ R. Raute
}

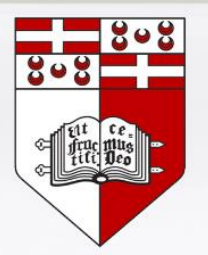




\section{Contents}

- System Overview

- Safety Requirements

- Sensorless Control

- Simulation Results

- Experimental Results

- Conclusion 


\section{Steer-by-Wire Overview}

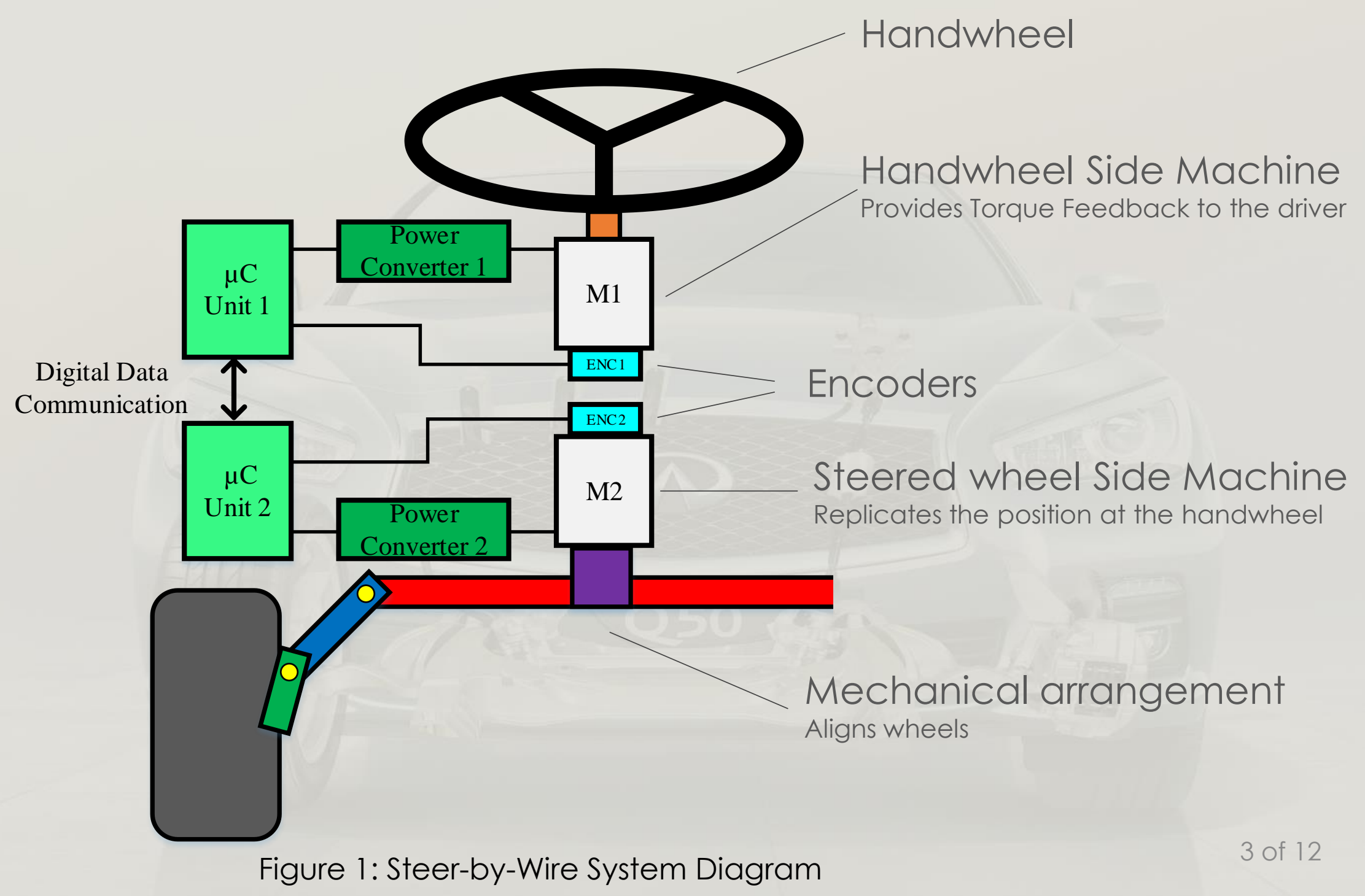




\section{Safety Requirements in Steer-by-Wire}

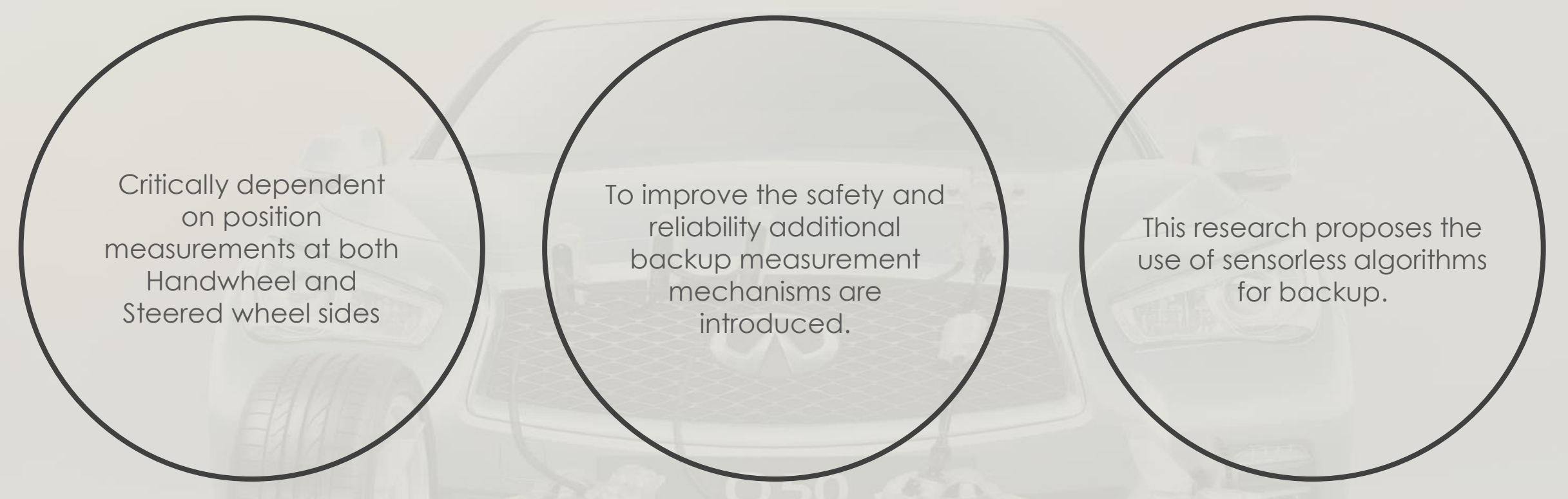




\section{Sensorless Control}
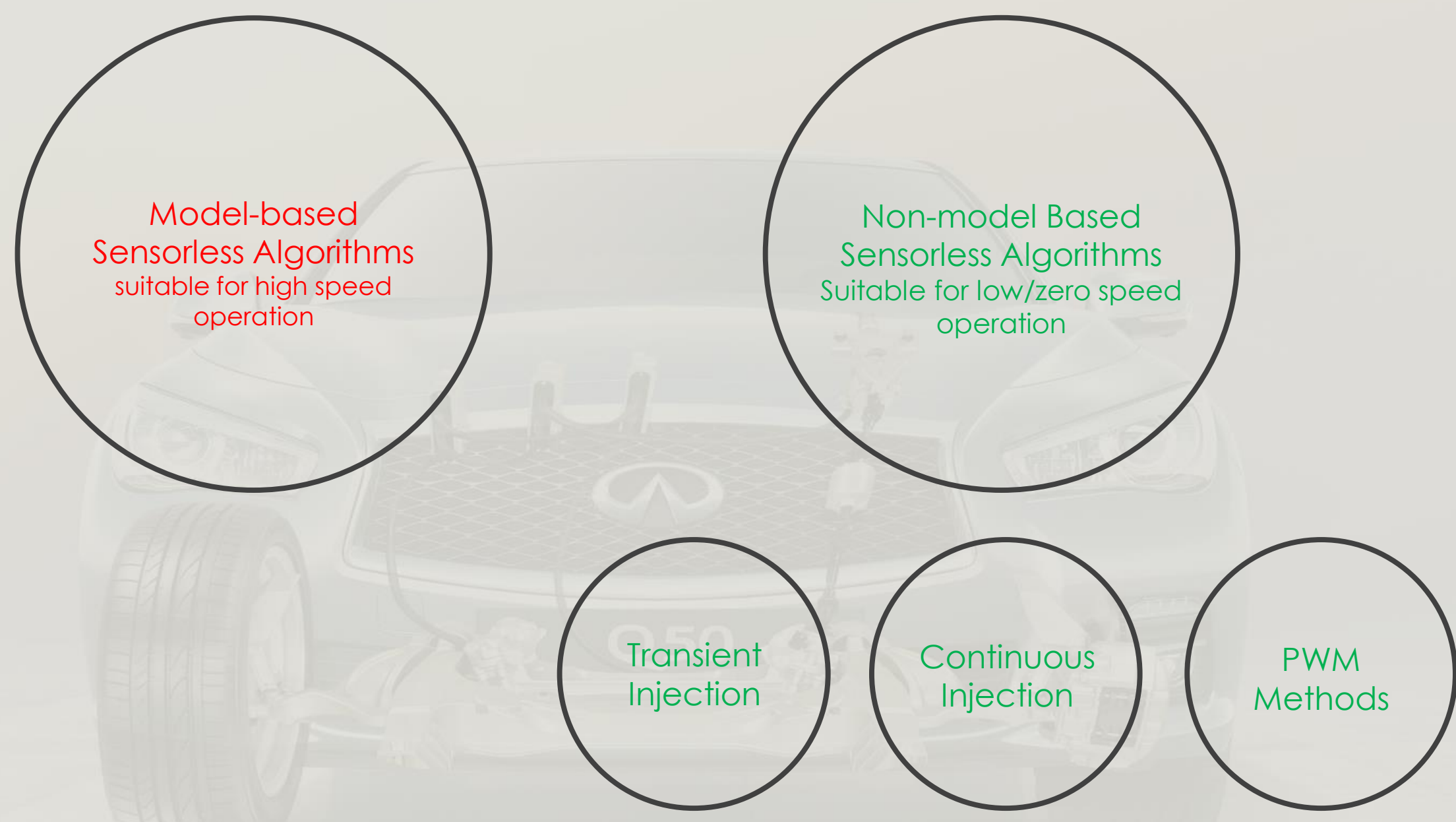


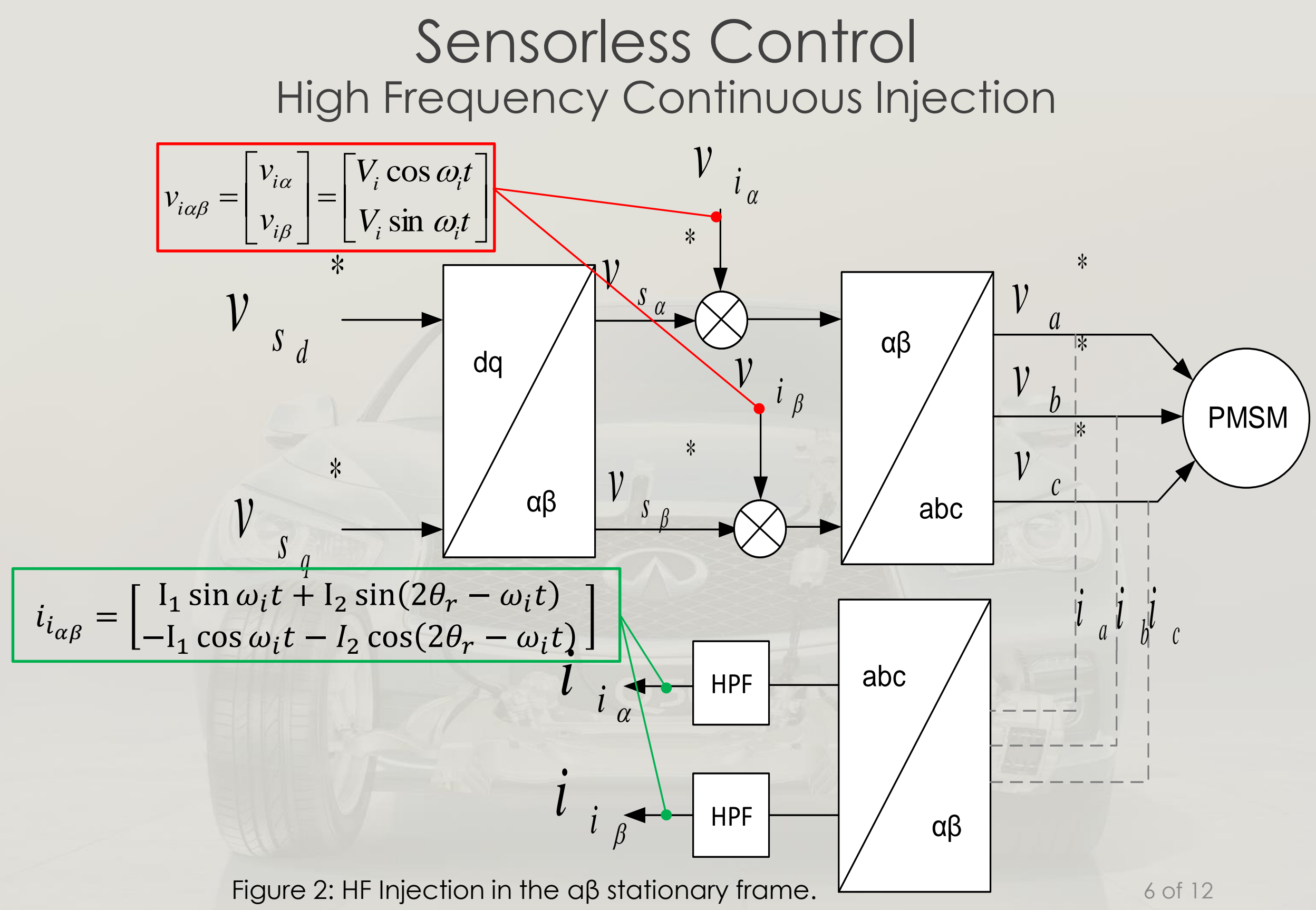




\section{Sensorless Control High Frequency Continuous Injection}

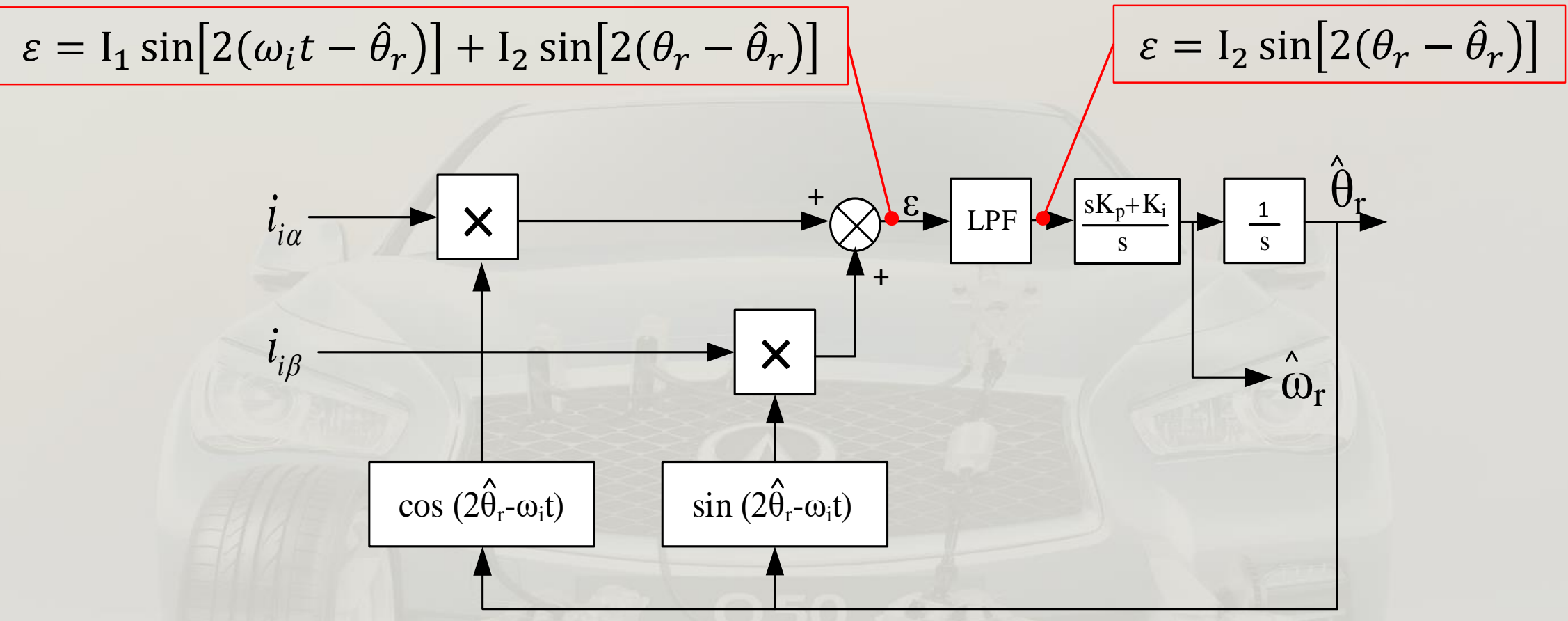

Figure 3: PLL rotor position/speed estimator with heterodyning. 


\section{Simulation Results for Simulink Model}
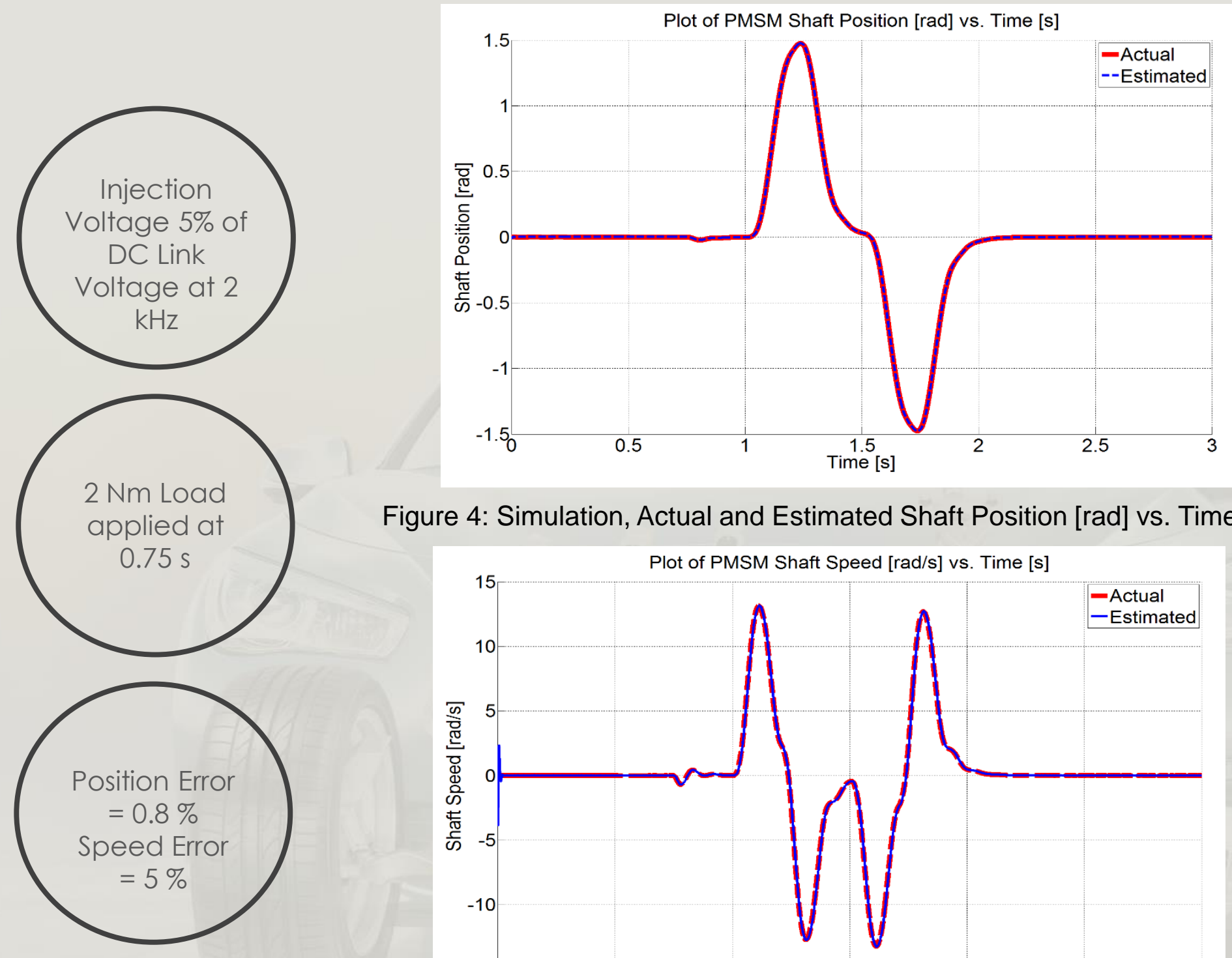

Figure 4: Simulation, Actual and Estimated Shaft Position [rad] vs. Time [s]

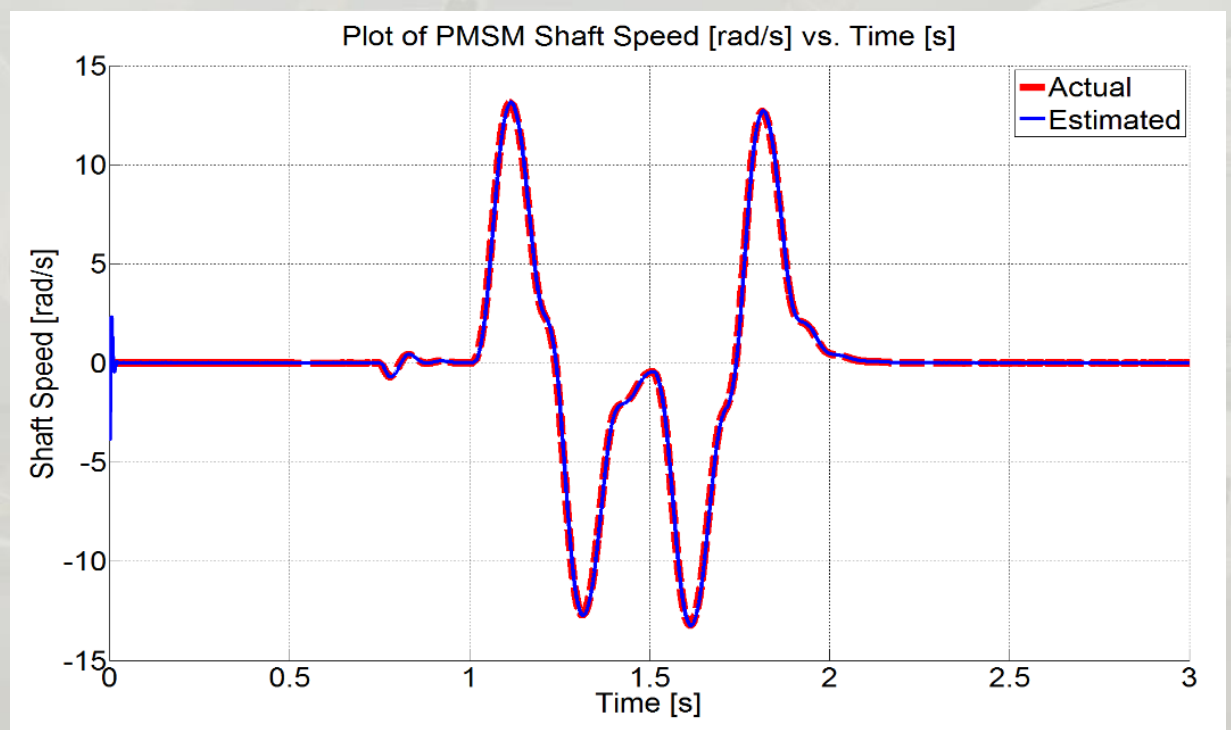

Figure 5: Simulation, Actual and Estimated Shaft Speed [rad/s] vs. Time [s] 


\section{Experimental Setup}

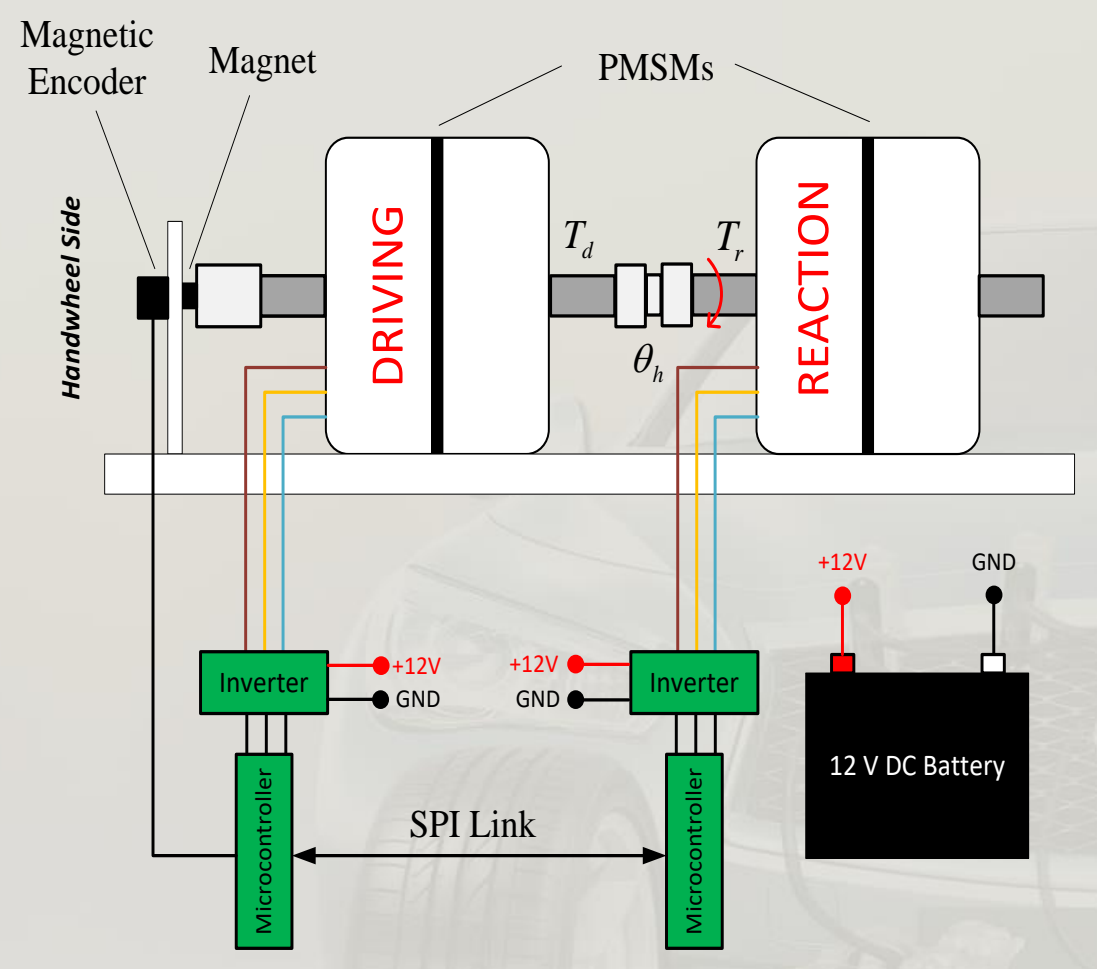

Figure 6: Steer-by-wire handwheel side setup illustration

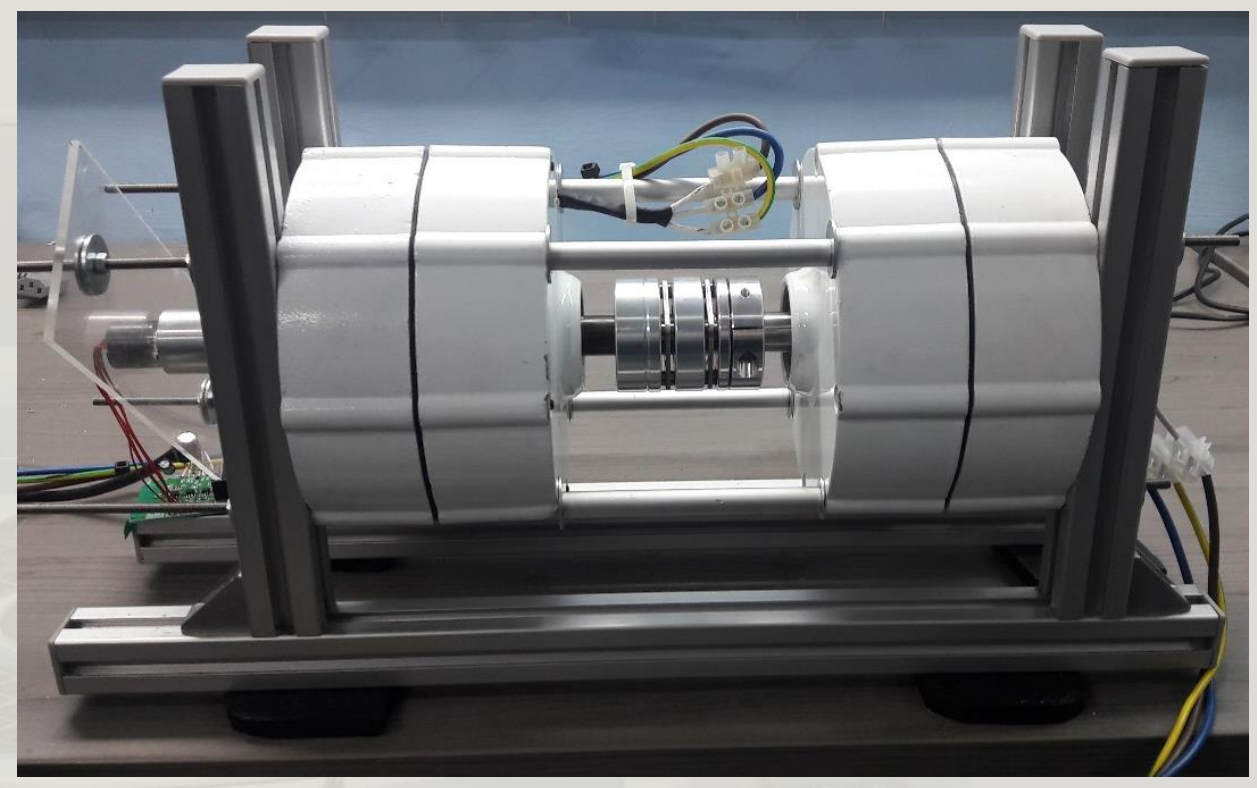

Figure 7: Steer-by-wire handwheel side PMSMs on experimental setup 


\section{Preliminary Experimental Results}
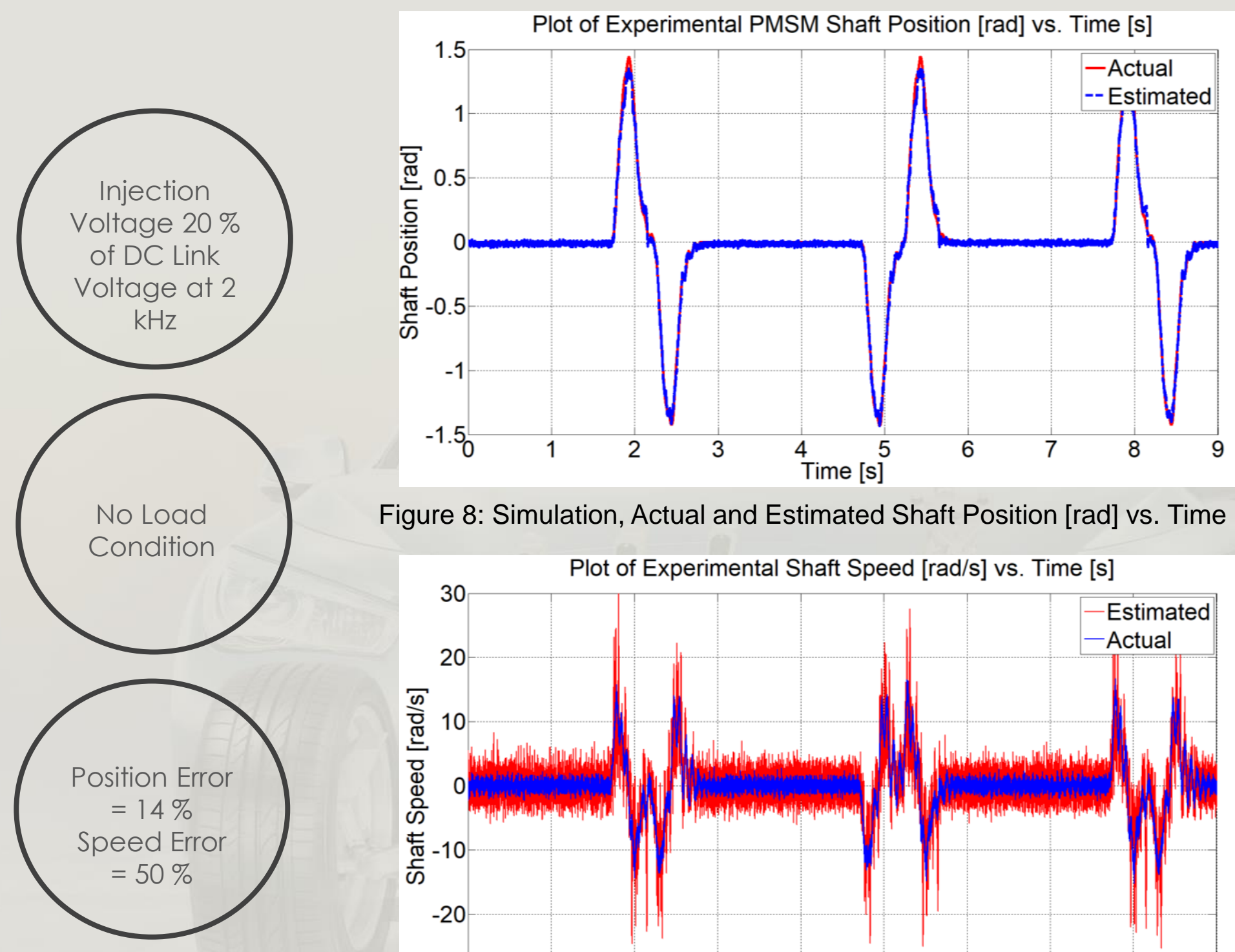

Figure 8: Simulation, Actual and Estimated Shaft Position [rad] vs. Time [s]

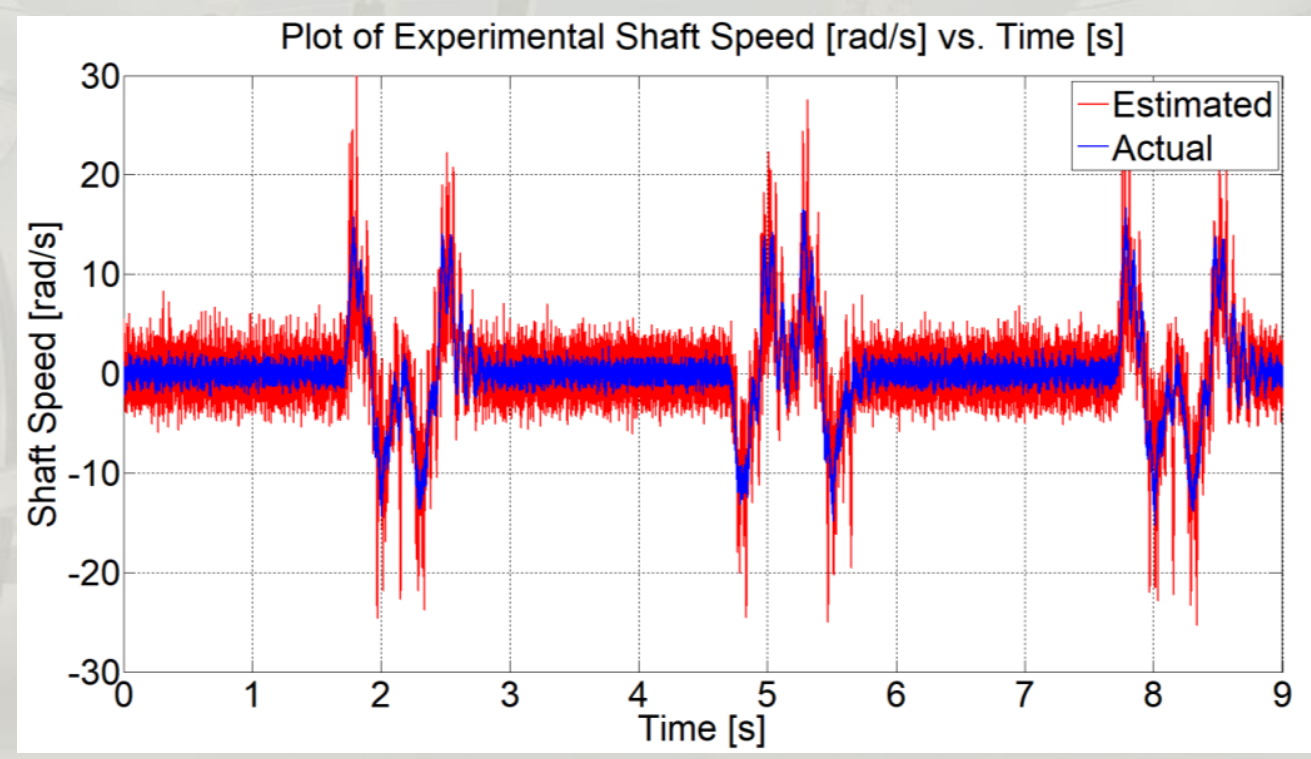

Figure 9: Simulation, Actual and Estimated Shaft Speed [rad/s] vs. Time [s] 


\section{Conclusions}
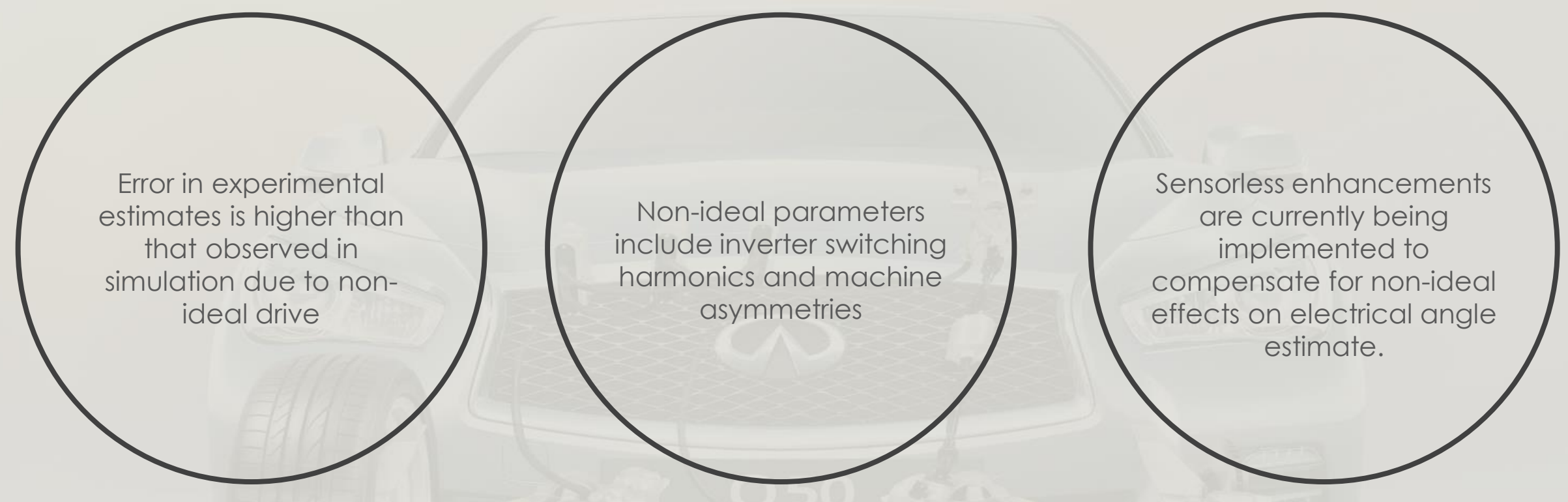


\section{Discussion}

\section{Authors}

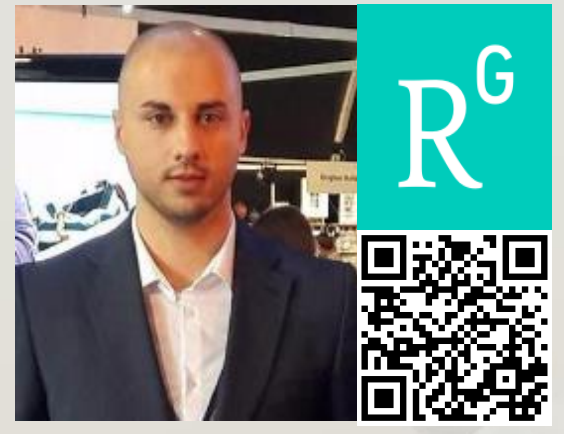

Kris Scicluna

PhD Research Student, Department of Industrial Electrical Power Conversion, University of Malta.

Lecturer, Institute of Engineering and Transport, Malta College for Arts, Science and Technology

Email: Kris.Scicluna@mcast.edu.mt

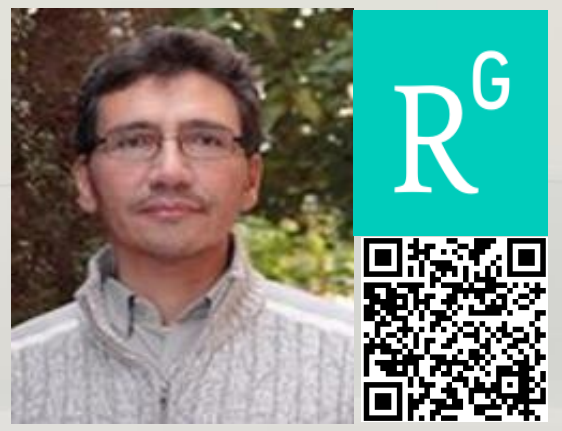

\section{Cyril Spiteri Staines}

Professor,

Department of Industrial Electrical Power Conversion University of Malta.

Email: cyril.spiteri-staines@um.edu.mt

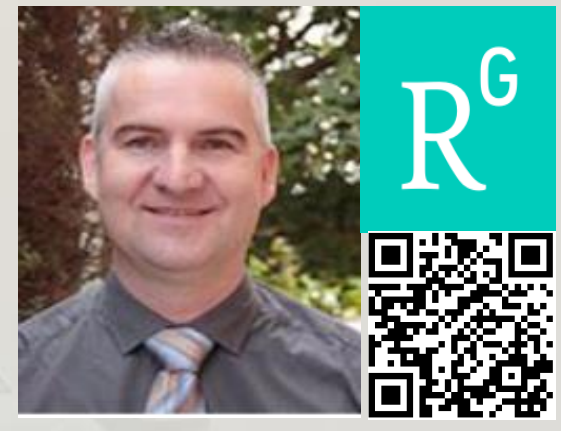

\section{Reiko Raute}

Lecturer,

Department of Industrial Electrical Power Conversion, University of Malta.

Email: reiko.raute@um.edu.mt

About the Department of Industrial Electrical Power Conversion - The Department of Industrial Electrical Power Conversion, IEPC, forms part of the Faculty of Engineering at the University of Malta. IEPC has been at the forefront of research and lecturing in the following areas of electrical engineering: Power Electronics and Distributed Generation; Power Systems and Grid Integration of Renewable Energy Sources (RES); Electrical Machines and Drives; and Electrical Services. Website: https://www.um.edu.mt/eng/epc

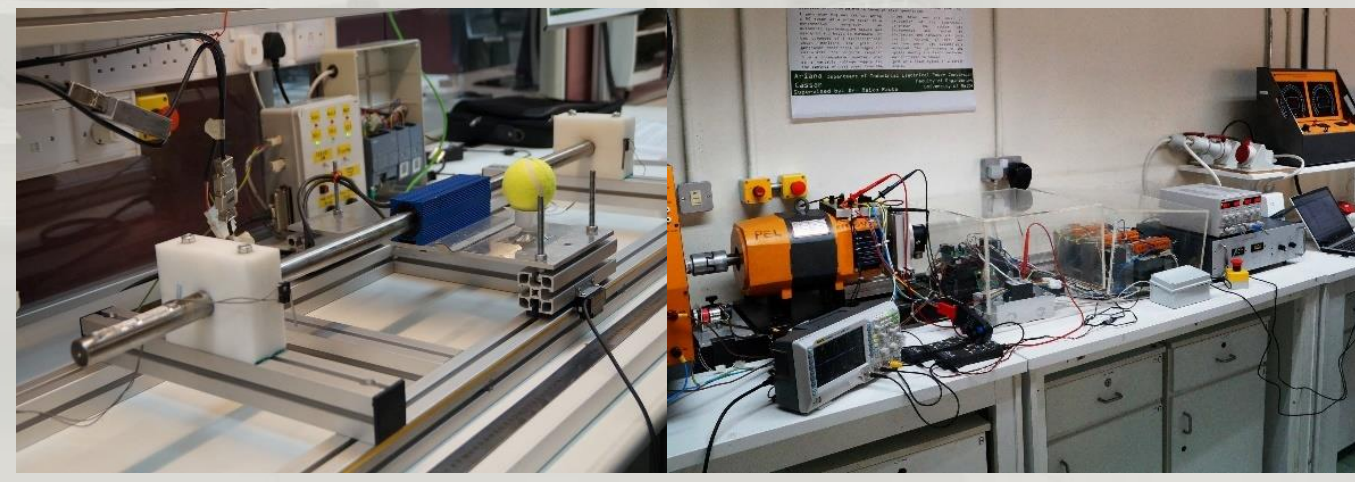

